\title{
Die Renchthalbăder.
}

Petersthal besitzt vier Quellen, welche sämmtlich in der Nähe der Rench aus Gneuss entspringen; die Stahloder Petersquelle, die Salz-oder Laxirquelle, die Gasoder Sophienquelle, und die Badquelle.

In neuester Zeit wurden diese Quellen vom Hofrath Dr. Bunsen einer neuen Analyse unterworfen, deren Resultate folgende sind:

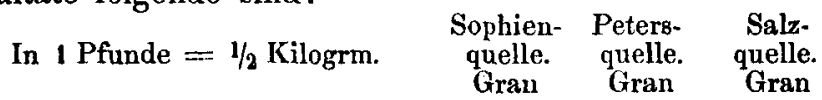

Zweifach-kohlens. Kalk . . . . . . . 10,577 11,713 11,580

$n \quad n \quad$ Magnesia . . . . $2,973 \quad 3,501 \quad 4,485$

n $n \quad$ Eisenoxydul . . . . $3,388 \quad 0,354 \quad \mathbf{0 , 3 4 6}$

$n \quad$ Lithion ...... $0,111 \quad 0,046 \quad 0,022$

$\begin{array}{llllllll}n & n & \text { Natron } . . . & . & . & \mathbf{0 , 5 1 2} & \mathbf{0 , 4 6 1} & \mathbf{0 , 2 8 1}\end{array}$

Chlornatrium. . . . . . . . . . . $0,233 \quad \mathbf{0 , 3 0 3} \quad \mathbf{0 , 3 5 0}$

Schwefelsaures Natron . . . . . 5,161 6,069 6,547

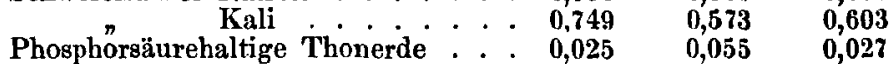

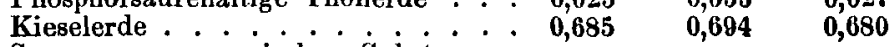

Spuren von organischen Substanzen

und Manganoxydu]

Summe der festen Bestandtheile 21,364 23,769 24,921.

Freie Kohlensäure *. . . . . . . . . 19,338 19,387 19,996

Bei $0^{0}$ und $0,76 \mathrm{M}$. Druck-Barometer oder Cubikzoll in 1 Pfunde . 33,16 33,2 34,2

Freier Stickstoff . . . . . . $0,004 \quad-\quad 0,008$

Bei $0^{0}$ und $0,76 \mathrm{M}$. Druck-Barometer oder Cubikzoll in 1 Pfunde. . 0,01 - 0,02

Specifisches Gewicht bei $19,5^{\circ}$ bei $26^{0}$ bei $26,6^{0}$

$\begin{array}{llll} & \text { Cels. } & \text { Cels. } & \text { Cels. } \\ \text { Temperatur nach Celsius bei }+15^{\circ} & 1,0031 & 1,0034 & 1,0034\end{array}$

Luftemperatur . . . . 8,90 10,30 $9,7^{\circ}$

Darnach stellt Bu nsen die Mineralquellen Petersthal's zu den stark eisenhaltigen, schwach alkalischen Säuerlingen; sie zeichnen sich sämmtlich durch einen ausserordentlichen Gehalt an Kohlensäure aus, indem sie so viel von diesem Gase enthalten, als sie den Absorptionscoëfficienten zufolge überhaupt aufzunehmen im Stande sind. Auch die sämmtlichen Petersthaler Quellen enthalten in ibren ocherigen Absätzen Spuren von arseniger Säure, wie die Incrustationen der meisten Mineralquellen.

Erlenbad. Nach der Analyse von Bunsen ist das Erlenbader Mineralwasser eine salinische, kochsalzhaltige Therme, für die sich auf 10,000 Theile folgende Zusammensetzung ergeben hat: 
Zweifach-kohlensaurer Kalk . . . . . . . . . 3,0737

Zweifach - kohlensaure Magnesia . . . . . . . 0,0798

Zweifach-kohlensaures Eisenoxydul . . . . . . 0,0426

Schwefelsaurer Kalk . . . . . . . . . . . . . $3, \mathbf{4 5 4 3}$

Schwefelsaure Magnesia

Schwefelsaures Natron . . . . . . . . . . . . 0,7303

Chlornatrium . . . . . . . . . . . . . . . 14,1361

Chlorkalium . . . . . . . . . . . . . . . 0,8293

Chlorlithium . . . . . . . . . . . . . . . . . 0,0644

Kieselerde . . . . . . . . . . . . . . . 0,2095

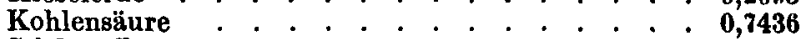

Stickstoff . . . . . . . . . . . . . . . 0,1149

Geringe Spuren von Mangan, Phosphorsäure, Jod aus organischen Stoffen .

$$
24,3103 \text {. }
$$

Das spec. Gewicht des Wassers ist bei $26^{\circ} \mathrm{C} .1,0034$. Dem Volumen nach finden sich in 1 Liter Wasser 37,18 Cubik-Centimeter freie Kohlensäure und 9,10 Cubik-Centimeter Stickstoff bei $0^{0}$ and $0,76 \mathrm{M}$. Barometerstand.

Die nachstehende Untersuchung der Incrustationen, welche die Quelle absetzt, hat ergeben, dass das Wasser eine geringe Menge arseniger Säure enthalten muss, wie man solche in neuerer Zeit in fast allen, besonders in den aus älteren plutonischen Gebilden stammenden Mineralquellen aufgefunden hat.

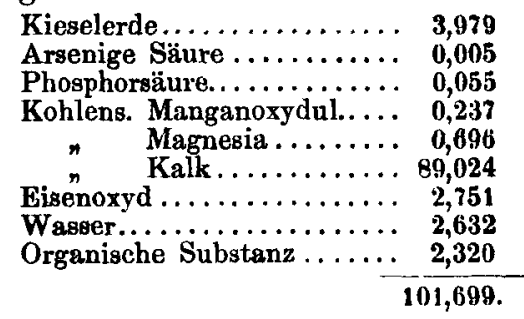

Der Arsenikgehalt des Wassers selbst ist indessen so gering, dass sich derselbe in 1000 Cubik-Centimetern durch keine Reaction mehr nachweisen liess. Nimmt man an, dass das Verhältniss des kohlensauren Kalks zur arsenigen Säure im Wasser dieselbe ist, wie in den Incrustationen, so kann in 5000 Litern oder eben so viel Weinflaschen voll Wasser noch kein voller Gran Arsenik vorhanden sein. Fs müsste daher ein Brunnengast 42 Jahre lang während zweier Monate täglich 2 Flaschen des Quellwassers trinken, um nur 1 Gran Arsenik in sich aufzunehmen.

In 1 bürgerlichen Pfunde des Mineralwassers sind folgende Bestandtheile in Granen und Cubikzollen:

Arch. d. Pharm. CXXXI.Bds. 2. Hft. 


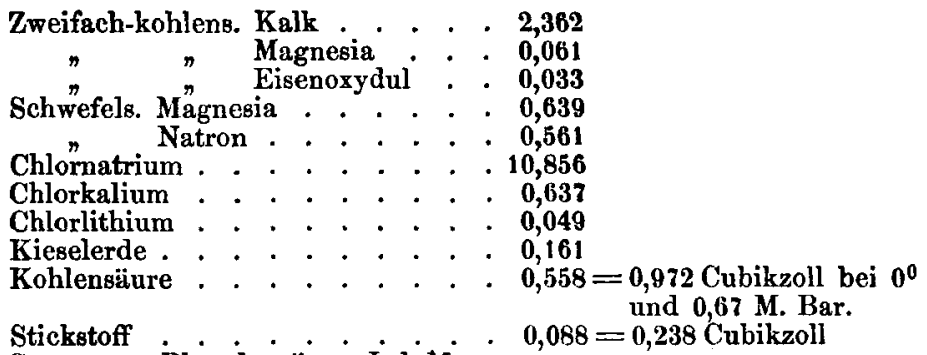

Spuren von Phosphorsäure, Jod, Man-

gan und organischer Substanz

(Mittheil. des bad. ärztl. Vereins. 1854.)

$B$.

\section{Veber einige Thonerde-Verbindangen.}

Walter Crum glaubt nicht an die Existenz der neutralen essigsauren Thonerde. Zersetzt man neutrale schwefelsaure Thonerde $\left(\mathrm{Al}^{2} \mathrm{O}^{3}+3 \mathrm{SO}^{3}\right)$ durch essigsaures Bleioxyd, so entsteht freie Essigsäure und basisches Acetat $\left(\mathrm{Al}^{2} \mathrm{O}^{3}+2 \overline{\mathrm{A}}\right)$.

Man erhält ein unlösliches, nach der Formel $\mathrm{Al}^{2} \mathrm{O}^{3}$, $+2 \overline{\mathrm{A}}, 2 \mathrm{HO}$ zusammengesetztes Thonerde-Acetat, wenn man concentrirte Lösungen und essigsaures Blei im Ueberschuss anwendet. Das neue Acetat scheidet sich ab, wenn man die filtrirte und von Blei und Schwefelsäure gehörig befreite Flüssigkeit der freiwilligen Verdunstung überlässt. Dieses Acetat bildet porcellanartige Scheiben. Lässt man es mit 200 Theilen Wasser sieden, so verwandelt es sich in freie Essigsäure, in Thonerdehydrat $\mathrm{Al}^{2} \mathrm{O}^{3}+2 \mathrm{HO}$ und in ein lösliches Salz, welches der Verf. nicht geprüft hat.

Wenn man bei niedriger Temperatur eine Lösung von essigsaurer Thonerde schnell verdanipft, so schlägt sich ein Acetat $\mathrm{Al}^{2} \mathrm{O}^{3}+2 \mathrm{~A}+4 \mathrm{HO}$ nieder, welches in Wasser vollständig löslich ist und sich, wie das vorhergehende, bei fortgesetztem Kochen zersetzt. So durch das Kochen modificirt, wirkte es nicht mehr beizend, seine Lösung kann durch eine Abkochung von Quercitron coagulirt werden, aber der gebildete Niederschlag ist farblos. Campeche- und Brasilienholz verhalten sich ebenso.

Das bei $100^{0}$ getrocknete Hydrat $\mathrm{Al}^{2} \mathrm{O}^{3}+2 \mathrm{HO}$ ist unlöslich in den concentrirten Säuren, löslich in Essigsäure und in reinem Wasser. Siedende Kalilauge verwandelt es in ein Hydrat von der Formel $\mathrm{Al}^{2} \mathrm{O}^{3}+3 \mathrm{HO}$. - Lässt 